\title{
Ricardo Palma: Arte y estilo narrativo al reescribir sus relatos breves
}

\author{
Eduardo Huárag Álvarez \\ Pontificia Universidad Católica del Perú \\ ehuarag@pucp.pe \\ Lima-Perú
}

\section{Resumen}

En este ensayo sustentaremos el porqué de la vigencia de las Tradiciones peruanas de Ricardo Palma. Advertimos la importancia de crear un formato que inserte un parrafillo histórico, como un modo de establecer una recreación que se base en hechos efectivamente acontecidos. Por otro lado, ahondamos en el cuidadoso trabajo de reescritura que hace el narrador a partir de los relatos de los cronistas. A través del análisis de tres tradiciones hacemos la comparación de las crónicas con los relatos de Palma para destacar su creatividad al recrear los hechos, animar posibles diálogos y el manejo de la intensidad narrativa para que no decaiga el interés por la lectura.

Palabras claves: tradiciones, Palma, crónicas, historia, Garcilaso.

\section{Abstract}

In this essay we will assess the validity of Ricardo Palma's Peruvian Traditions. We note the importance of creating a format that inserts a historical paragraph, as a way of establishing a recreation that is based on events that have occurred. On the other hand, we delve into the careful rewriting work that the narrator does from the stories of the chroniclers. Through the analysis of three traditions, we compare the chronicles with Palma's stories to highlight their creativity in recreating the events, encouraging possible dialogues, and managing narrative intensity so that interest in reading does not wane.

Keywords: traditions, Palma, chronicles, history, Garcilaso. 


\section{Eduardo Huárag Álvarez (Perú)}

Doctor en Lengua y Literatura por la Pontificia Universidad Católica del Perú. Maestría en Comunicaciones por la Universidad de Andalucía (España). Profesor Asociado del departamento de Humanidades de la Universidad Católica del Perú. Ha sido profesor visitante en la Universidad de Burdeos, la Universidad de Múnich y la Universidad de Sao Paulo. Ha publicado La cultura oral en la narrativa hispanoamericana, Mitos de origen y el trasmundo en las culturas prehispánicas y amazónicas, entre otros. 


\section{Introducción}

A pocos meses de celebrar el Bicentenario de la Independencia del Perú, es oportuno revisar la importancia de Ricardo Palma en la configuración de la nacionalidad. Nos tenemos que preguntar: ¿Por qué trascendieron sus Tradiciones peruanas al punto que se han convertido en clásicos de la literatura peruana?

La primera constatación que hacemos es que los relatos de Palma se refieren a hechos anecdóticos, episodios breves de la historia del país, especialmente ocurridos en el periodo colonial. Palma no le cuenta al lector hechos o peripecias de su presente (siglo XIX y parte del XX). Ese afán de escribir acontecimientos ocurridos en el pasado se debe a su filiación a los románticos, quienes recreaban acontecimientos ocurridos en tiempos idos. Palma cree que existe una continuidad histórica del virreinato a la república. Lo que sucede en el presente es una heredad que tiene su origen en el pasado. Es decir, conociendo el pasado, se entenderá mejor el presente.

Pero hay otro vacío que encuentra el narrador en la configuración de la historia nacional. Observa el narrador que la historia nacional es muy formal y que no consigna hechos y episodios que terminan siendo significativos para la conciencia popular. Así pues, lo que hace Palma es reescribir la historia. Aborda con su estilo, la inserción de refranes y giros costumbristas, una historia amena que, seguramente, los lectores recibirán con interés.

Palma es un investigador acucioso de la historia nacional. Estará bien enterado de las crónicas de personajes y hechos acontecidos en tiempos de la Colonia. De manera que allí encuentra varios personajes -como Francisco de Carvajal-sobre quienes considera necesario escribir. La historia oficial apenas lo menciona porque no se llamó Francisco Pizarro, Pedrarias u Orellana. Él lo convierte en personaje-leyenda. 
En este artículo nos proponemos mostrar algunas consideraciones iniciales acerca de los vínculos (o quizá mejor, relaciones de dependencia) entre las crónicas y las Tradiciones peruanas. Por eso analizaremos tres de sus tradiciones que se basaron en crónicas; casos de reescritura en los que se pone en evidencia la diferencia paradigmática.

No desconocemos que, en esta misma línea, Merlin Compton (2000) inició los estudios que relacionan las crónicas con las Tradiciones peruanas. Y antes de él, también tenemos como referente el estudio que realizó el desaparecido profesor José Miguel Oviedo (1965), crítico importante del siglo XIX y, en realidad, de la literatura latinoamericana.

\section{Consideraciones fundamentales y el enlace con los relatos populares}

Palma no escribe por la simple afición de recrear un hecho episódico. El narrador se desenvuelve en el paradigma literario, distinto al del paradigma que tiene un cronista. Recrea una peripecia, con creatividad y estilo; pero, le hace ver al lector que hay una continuidad en las costumbres, los modos de ser del ciudadano común y corriente. Así pues, el narrador constata, con frecuencia, que la herencia cultural se mantiene vigente y fue asumida especialmente por la población criolla, que tuvo el control político de la nación.

Para Palma, la Independencia no significó un corte radical frente a la cultura que difundieron los colonizadores. No se podía negar la historia virreinal. Querámoslo o no, eso era parte de esa larga tradición social y cultural que hemos heredado. Y era tan cierto que el narrador encontrará la forma de enlazar el episodio acontecido en el pasado con el presente del lector. No es una historia del pasado que se queda en el pasado. Palma 
lo proyecta al presente y un refrán o el nombre de la calle da motivo para recordar hechos anecdóticos que se difunden en el imaginario popular.

Así pues, se establece una especie de vaso comunicante entre lo acontecido en el pasado y lo que se constata en el presente, siendo el refrán uno de los puentes significativos. Ello hace que una tradición no sea una simple referencia anecdótica. Allí está presente la idiosincrasia de un pueblo, y ciertas costumbres positivas y negativas. No olvidemos, por ejemplo, cómo es que la organización semifeudal -en la propiedad y trabajo de la tierra- heredada de los españoles se mantuvo décadas después del inicio de la República.

Pero también heredamos la gracia y el humor acriollado. Los personajes que pueblan el imaginario popular son parte también de las tradiciones. Palma encuentra el gusto de contar cuando recrea hechos episódicos o anecdóticos acerca de algunos virreyes, pero también de los libertadores y la leyenda que surgió en torno a ellos y las mujeres de su entorno. Eran historias trasmitidas por los viejos. Por cierto, Palma encuentra el estilo apropiado para que lo relatado sea ameno a la vez que reflexivo.

\section{Acerca de la estructura de las tradiciones peruanas}

Muchos críticos vincularon a Palma al costumbrismo. No lo negamos del todo, pero hay que hacer algunas distinciones. Mientras los costumbristas de su época (siglo XIX) focalizan un episodio acontecido en el presente, siendo el propósito ridiculizar o exaltar el modo propio de ser de los ciudadanos de Lima, Palma focaliza también episodios anecdóticos, pero enlaza, en sus tradiciones, aquello que él llama el «parrafillo histórico». Ese es un estilo propio del formato que él identificó 
como tradiciones peruanas. Palma lo que hace es reescribir los hechos del pasado, le da un tono de humor, pero siempre buscando un enlace entre el pasado y el presente.

José Miguel Oviedo, uno de los estudiosos más importantes de la obra palmista, decía que:

Su tradición tiene tres partes o instancias. En la primera presenta la historia que va a narrar o pinta el ambiente [...].

La segunda es el consabido «parrafillo histórico» donde se proporcionan los datos ciertos que dan verosimilitud al relato; es una digresión histórica que sirve como punto de apoyo para que la imaginación vuele después. No siempre tenía que ver con el asunto que se narraba, ni tampoco suele parecer oportuno esa larga parrafada de información. El tono se hacía un tanto más frío y serio [...].

Tras ese suspenso, venía la tercera y última parte donde Palma redondeaba la anécdota introduciendo diálogos, abundantes dichos y refranes y la infaltable moraleja o lección del asunto (1965, p. 170).

Lo dicho por Oviedo se cumple en ciertas tradiciones, pero no es posible generalizar porque, por ejemplo, en «Las orejas del alcalde», la primera parte es más que la simple referencia al ambiente en que sucedieron los hechos. Creo que luego de una brevísima referencia de la localidad minera se pasa al diálogo del alcalde con los detenidos y allí se produce lo que en narrativa llamamos el hecho desencadenante. Eso que Oviedo señala como tercera parte ya se muestra desde antes del parrafillo histórico.

Esta observación la hicimos en una publicación anterior:

Este esquema que ha sido repetido por muchos analistas, como si fuese un patrón invariable, en realidad no se aplica de modo invariable. Ni el parrafillo histórico aparece como 
tal en todas las tradiciones y menos suele tener la misma extensión en todos los relatos. Lo había advertido también Carlos Eduardo Zavaleta (1998), en un discurso, cuando señala que: «En casi la mayoría de los textos que he citado no encaja la supuesta estructura de la tradición...» (Zavaleta, citado por Huárag, 2004, p. 18).

Naturalmente, los creativos se caracterizan por romper los esquemas establecidos. Y Palma es uno de esos que exploran diversos modos de contar. Su extraordinaria intuición estética (su idea de relato) y la noción de cuándo y cómo intensificar los hechos del relato dependen de su creatividad. Él sabe cuándo y cómo incluir el denominado «parrafillo histórico», aun cuando esa secuencia narrativa parece que detiene la intensidad de acción del relato.

Respecto a ciertas costumbres que retratan lo que sucedía en cuanto a las querellas de honor, se ve reflejado en «Un litigio original». En Lima, capital del virreinato, vivían muchos funcionarios españoles que venían de la península con sus títulos de marqués o duque. Y fue el caso que, cuando circulaban por la ciudad se encontraron dos carretas y ninguno quiso retroceder para darle el pase al otro. En ese momento, salió a relucir quién es el que debe retroceder. Ambos creen que tienen un estatus social que está por encima del impertinente que se le ha cruzado en el camino. Ellos exigen a sus siervos que no retrocedan. Pasaba el tiempo y se sugirió que fueran ante el virrey para que resuelva el litigio. La autoridad, para no enemistarse con los notables, prefirió remitir el caso a la corte de los reyes. La resolución tarda más de un año y, cuando llega, si bien da satisfacciones a uno de los litigantes, ambas carretas habían sido saqueadas y no había nada rescatable. Si proyectamos al presente la significación del litigio se puede apreciar que cuando se produce una discusión entre dos personas no es raro que uno de ellos diga: «Tú no sabes con quién estás hablando». 


\section{Las crónicas del Inca Garcilaso de la Vega y las tradiciones de Ricardo Palma}

Nos parece necesario hacer una comparación entre el Inca Garcilaso de la Vega, autor de los Comentarios reales, y Ricardo Palma, autor de las Tradiciones peruanas. En la introducción de este trabajo afirmamos que muchos de los relatos breves de Palma son una reescritura de los incidentes y hechos anecdóticos registrados en las crónicas. Cada uno, en su estilo, narró acontecimientos ocurridos en tiempos de la colonia. Mientras el cronista, como historiador, debía registrar los hechos acontecidos en tiempos de la conquista y la historia de los Incas, que recogieron de oídas, Palma -que no vivió en los tiempos del virreinato- investigó y recreó las historias $\mathrm{y}$ personajes que fueron de su preferencia, pero siempre con el ánimo de construir un relato literario, ameno y bien estructurado.

Al comparar al Inca Garcilaso con Palma podemos advertir que ambos son escritores que salen del encasillamiento del género que cultivan. El Inca Garcilaso no se restringe al registro de hechos y acontecimientos del incanato. Garcilaso cala en los aportes de los incas y preíncas acerca del tratamiento de enfermedades, sus conocimientos en la construcción de ciudadelas, y claro está, la manera cómo entendían la vida, el mundo y el mas allá. Pero además -y es lo que nos interesa resaltar-Garcilaso se sale del frío estilo de los cronistas y agrega breves relatos, como la historia del náufrago Pedro Serrano. Garcilaso encuentra gusto en el acto de contar un episodio anecdótico. Claro, destaca también su estilo al presentarse como narrador directo: yo vide tal o cual hecho. O cuando dialoga con su tío -por la línea materna- acerca de lo que fue el imperio incaico.

Palma, a su vez, no se restringe al relato del episodio, a la recreación que solían hacer los narradores costumbristas. Estos 
últimos escribían para llamar la atención de un manifiesto cultural importante o para criticar o burlarse de algún personaje de la época. Palma crea un formato nuevo al incluir en su relato lo que él llama «parrafillo histórico». Tal vez el escritor pensaba que, de ese modo, su recreación ficcional ganaba en verosimilitud y que los hechos dramatizados no serían vistos como propuestas artificiosas o conjetura sin base histórica.

Sucede que cuando uno empieza a indagar acerca de la relación que puede haber entre las tradiciones y las crónicas, se encontrará con que la obra de Palma es, prácticamente, una reescritura de los hechos y episodios. La comparación nos permitirá apreciar los recursos que utiliza el escritor para hacer de su relato una narración interesante, sugestiva y amena.

Entonces, de la historia mantendrá el argumento central, pero su tratamiento difiere del propósito de un cronista. No olvidemos que el cronista tiene como objetivo el recuento de hechos de manera objetiva; mientras que al narrador lo que le interesa es que el relato sea atractivo desde la perspectiva literaria, artística. Al narrador no le interesa sujetarse a la verdad objetiva. La narración puede sufrir cambios significativos, algunos nombres distintos o un desenlace diferente al que propone la crónica.

Cuando Palma comenta sus tradiciones, como obra particular desde el punto de vista del formato creado, advierte que es una tarea laboriosa. En una carta que le dirige a Vicente Barrantes, dice:

A mis ojos, una tradición no es un trabajo que se trata a la ligera, es una obra de arte. Tengo una paciencia de benidictino para limar y pulir mi frase. Es la forma, más que el fondo, lo que las torna populares (citado por Oviedo, 1965, p. 153). 
Pareciera que, para el narrador, lo ficcional se ajusta a la novela; mientras que sus relatos breves podían estar enlazados a hechos históricos (lo que justificaría el denominado «parrafillo histórico»). En una carta dirigida a Carlos Robinet dice:

Nunca he aspirado a pasar por original en la creación de un argumento. Esa cualidad de la fantasía conviene al novelista; pero no a quien, como yo, vive en el enmarañado campo de la historia. Mis tradiciones, más que mías, son de ese cronista que se llama el pueblo, auxiliándome, y no poco, los datos y noticias que en pergaminos encuentro consignados... Soy un pintor que restaura y da colorido a cuadros del pasado (Carta de enero de 1878, consignada por Oviedo, 1965, p. 128).

\section{La reescritura de algunos relatos consignados por los cronistas}

\subsection{Acerca de la reescritura de «Carta canta» o cuando la escritura reveló la transgresión cometida}

El relato que da pie a la tradición «Carta canta» figura en Comentarios reales del Inca Garcilaso de la Vega (2007, p. 848). El cronista señala, a su vez, que la historia la encontró en los escritos de José de Acosta ([1590] 2008). También es importante advertir que el Inca Garcilaso lo consigna en su obra bajo el título «De las hortalizas y yerbas y de la grandeza dellas» (2007, p. 849).

Según el episodio anecdótico, los hechos se inician cuando el capataz de una hacienda decide enviar a su amo, los melones recogidos en la cosecha. La hacienda estaba ubicada en Pachacámac y el propietario era Antonio Solar. Según lo referido, el capataz español: 
Envió a su amo diez melones que llevaron dos indios a cuestas, según las costumbres dellos, con una carta. A la partida le dijo el capataz: «No comáis ningún melón déstos, porque si lo coméis lo ha de decir esta carta» (ibíd., p. 851).

Pero la tentación por comer la fruta fue irresistible. Uno de ellos propone probar los frutos que llevan como carga. El compañero de viaje no estaba de acuerdo: «No porque si comemos alguno, lo dirá esta carta, que así nos lo dijo el capataz» (ibíd.). Replicó el primero: «Buen remedio, echemos la carta detrás de aquel paredón, y como no nos vea comer, no podrá decir nada» (ibíd.).

Obsérvese que desconociendo ellos la escritura la identificaban como un ser viviente que podría mirarlos y denunciar la falta. Esta actitud es parte del animismo que solían tener los nativos.

Luego que comieron, aún tenían ganas de seguir con otro melón. Entonces, uno de los nativos dijo:

«No vamos acertados, conviene que emparejemos las cargas, porque si nos lleváis cuatro y yo cinco, sospecharán que nos hemos comido el que falta». Dijo el compañero: «Muy bien decís». Y así, por encubrir un delito, hicieron otro mayor, que se comieron otro (ibíd.).

Una vez que llegaron a la casa del amo, este recibió el envío $\mathrm{y}$ se puso a leer la carta. Vio los melones y al contarlos reaccionó: «¿Qué son de dos melones que falta aquí? Ellos a una respondieron: "Señor, no nos dieron más de ocho". Dijo Antonio Solar: "¿Por qué mentís vosotros, que esta carta dice que os dieron diez y que os comisteis dos?”»(ibíd., p. 852).

Cuando Palma procede a la reescritura de este relato, le pone como título «Carta canta». Sin duda, haciendo alusión a esa frase que aún tenía vigencia en esa época y que, años después, con los criollos en el poder, devendría en «papelito manda»: 
Hasta mediados del siglo XVI vemos empleada por los más castizos prosadores o prosistas castellanos esta frase: rezan cartas, en la acepción de que tal o cual hecho es referido en epístolas. Pero de repente las cartas no se conforman con rezar, sino que rompieron a cantar, y hoy mismo, para poner remate a una disputa, solemos echar mano al bolsillo y sacar una misiva, diciendo: -Pues, señor, carta canta. Y leemos en público las verdades o mentiras que ella contiene, y el campo queda para nosotros. Lo que es la gente ultracriolla no hace rezar ni cantar a las cartas, y se limita a decir: papelito manda (Palma, 1968, pp. 146-147).

Nótese la importancia que le concede Palma a la frase que, como sabiduría popular, se ajusta a diversas situaciones en las que un escrito, como el caso de los nativos que se comieron los melones, determina qué es lo válido.

Ahora bien, cuando Palma reescribe el relato, le interesa recrear el ambiente, la atmósfera que acompaña a los mitayos mientras van por los caminos hasta llegar a la casa del amo. En su desconocimiento de lo que es la palabra escrita, además ingenuamente, creen que con esconder la carta no habrá testigos que observen la falta que están cometiendo:

Habían avanzado los conductores algunas leguas, y sentáronse a descansar junto a una tapia. Como era natural, el perfume de la fruta despertó la curiosidad de los mitayos, y se entabló en sus ánimos ruda batalla entre el apetito y el temor.

- ¿Sabes, hermano -dijo al fin uno de ellos en su dialecto indígena-, que he dado con la manera de que podamos comer sin que se descubra el caso? Escondamos la carta detrás de la tapia, que no viéndonos ella no podrá denunciarnos (ibíd., p. 148) 
Pero la tentación no se detiene solo en la sustracción de un melón. Quieren más y surge otro motivo como para justificar el hecho de que se coman otro melón:

-Hermano, vamos errados. Conviene que igualemos las cargas, porque si tú llevas cuatro y yo cinco, nacerá alguna sospecha en el amo.

-Bien discurrido -dijo el otro mitayo.

Y nuevamente escondieron la carta tras otra tapia, para dar cuenta de un segundo melón (ibíd., p. 148).

Obsérvese la importancia que le concede Palma a la recreación de lo acontecido. La misma adecuación del habla de los personajes hace ver que Palma ha tenido que recurrir a un modo discursivo que se asemeje al lenguaje y estilo de habla de esos tiempos; pero a la vez las expresiones oracionales suponen una modificación de ese castellano viejo que utilizaba el Inca Garcilaso. Entre el lenguaje y estilo de uno y otro había de por medio tres siglos de uso del castellano.

Y como para que se observe la diferencia del estilo de un cronista y el de un narrador, obsérvese cómo presenta el desenlace el Inca Garcilaso y cómo lo hace Palma. Para el Inca Garcilaso es la simple lectura que ha hecho el amo y que lo que ha llegado no es lo que se señala en el escrito y decide que se les castigue. En cambio, para Palma, el desenlace da motivo a un diálogo en el que los nativos insistirán en que solo fueron ocho.

-iCómo se entiende, ladronzuelos!... -exclamó bufando de cólera-. El mayordomo me manda diez melones, y aquí faltan dos -y don Antonio volvía a consultar la carta.

-Ocho, no más, taitai -contestaron los mitayos. 
-La carta dice que diez y ustedes se han comido dos por el camino... iEa! Que les den una docena de palos a estos pícaros.

Y los pobres indios, después de bien zurrados, se sentaron mohínos en un rincón del patio, diciendo uno de ellos:

¿Lo ves hermano? iCarta canta! (ibíd.).

En suma, la sensación que nos deja la comparación de los relatos, es que Palma aprovecha para ambientar, para introducir diálogos que hacen más verosímil lo acontecido entre los mitayos. Sin duda, Palma recrea y recurre a un estilo y una estrategia propia de la narrativa moderna.

\section{2. «Las orejas del alcalde»: el honor mancillado y la venganza inevitable}

El Inca Garcilaso de la Vega consigna un relato que aparece en el capítulo XVII de los Comentarios reales. Como ocurría en la época, a veces el narrador iniciaba la historia en un capítulo y continuaba en el siguiente. Es lo que sucede en este caso. Según el cronista:

Y fue que cuatro años antes, saliendo de Potocsi una gran banda de doscientos soldados para el reino de Tucma, que los españoles llaman Tucumán, habiendo salido de la villa los más dellos con indios cargados, aunque las provisiones de los Oidores lo prohibían, un alcalde mayor de la justicia que gobernaba aquella villa, que se decía el Licenciado Esquivel, que yo conocí, salía a ver los soldados cómo iban por sus cuadrillas; y habiéndoles dejado pasar todos con indios cargados, echó mano y prendió al último dellos, que se decía fulano de Aguirre, porque llevaba dos indios cargados, y pocos días después lo sentenció a doscientos azotes, porque no tenía oro ni plata para pagar la pena de la provisión a los que cargaban indios (2007, tomo II, p. 924). 
Como se nos hace saber, el procedimiento de llevar a indios con carga estaba prohibido, y sabiéndolo, el alcalde les reclamaba un pago en oro o plata a cambio de no interrumpirles el camino. Y el caso es que uno de ellos fue retenido y como no tenía cómo pagar por la falta que cometía le aplicaron doscientos azotes.

El apresado era un hidalgo que recibió los azotes como una ofensa a su posición social. De manera que, en esos casos, el humillado solo esperará de qué modo vengará el deshonor. Se trataba, en lenguaje de la época, de una afrenta y él no iba a quedarse pasivo.

Convencido de buscar venganza le perseguiría para matarle: «[... cumplido el término del oficio del Licenciado Esquivel, dio en andarse tras él como hombre desesperado, por matarle como quiera que pudiese, por vengar una afrenta» (ibíd., p. 926).

Cuando el licenciado se enteró de que el soldado sancionado tramaba venganza decidió irse de Potosí: «Mas él cobraba tanto más ánimo cuanto más el Licenciado le huía, y le seguía por el rastro dondequiera que iba» (ibíd.).

Está claro que se trata de una afrenta y que el afectado iniciará un asedio al que le dio de azotes. Y lo peor, Aguirre cree que la única manera de resolver la afrenta sería matándolo. El Licenciado huía, pero Aguirre aparecía en el lugar menos esperado. Primero fue a Lima, y allí apareció Aguirre. Fue entonces a Quito y:

A poco más de veinte días estaba Aguirre en ella, lo cual sabido por el Licenciado volvió, y dio otro salto hasta el Cosco, que son quinientas leguas de camino, pero pocos días después vino Aguirre, que caminaba a pie y descalzo y decía que un azotado no había de andar a caballo ni parecer donde gentes lo viesen. Desta manera anduvo Aguirre tras su licenciado tres años y cuatro meses (ibíd., p. 927). 
El caso es que en algún momento lo encontraría en las condiciones que él esperaba:

Le halló durmiendo sobre uno dellos y le dio una puñalada en la sien derecha, de que lo mató; y después le dio otras dos o tres por el cuerpo, mas no le hirió por la cota que tenía vestida, pero los golpes se mostraron por las roturas del sayo (ibíd., p. 927).

El acto de venganza se había consumado. Muerto el licenciado, Aguirre tenía que huir. Consigue algunos amigos que le oculten, pero, pasado un tiempo, sus protectores vieron la necesidad de deshacerse de él. Entonces se acordaron de una celebración local y decidieron que podría ir disfrazado:

Para lo cual le raparon el cabello y la barba y le lavaron la cabeza, el rostro y el pescuezo y las manos y brazos hasta los codos, con agua en la cual había echado una fruta silvestre, que lo dejó negro por varios días (ibíd., p. 930).

Fue de ese modo como Aguirre salió del Cuzco. Los que le dieron protección se despidieron de él: «Hermano, ya estáis en tierra libre, que podéis iros donde bien os estuviere, que yo no puedo hacer más por vos» (ibíd., p. 930).

Veamos ahora cuál es el tratamiento o reescritura que le dio Palma al mismo relato. Para empezar, Palma introduce no solo la inmoral situación ventajosa que lleva a la autoridad a pedir una especie de «comisión» para no retenerlos por el delito que estaban cometiendo. Pero, además, acorde con el romanticismo al que estaba adscrito, introduce la motivación amorosa entre los motivos que impulsan al Licenciado a cometer la sanción contra Aguirre. En el caso del relato de Palma, ese personaje cambia de nombre y será Cristóbal de Agüero. En su relato, Palma cuenta que el Licenciado alcalde de Potosí estaba 
prendado de una joven potosina que no le hacía caso por estar en amores con el soldado que prestaba servicios en Tucumán. Y entre los transgresores de las normas estaba nada menos que Cristóbal de Agüero, el enamorado de la joven potosina.

Antes de la captura del soldado, el narrador ha dado información de Potosí y advierte que como todo pueblo minero está lleno de lugares de entretenimiento y apuestas que terminaban en pugilatos y reyertas. Entonces recurre a una frase conocida: «Pueblo minero -dice el refrán- pueblo pendenciero. Y nunca tuvo refrán más exacta verdad que tratándose de Potosí en los dos primeros siglos de la Conquista» (1968, p. 123).

Continuando con el relato, el alcalde le advierte que debe pagar si no quiere sufrir azotes por la falta cometida. Esta escena, en la crónica, es muy breve. Palma la recrea a través del supuesto diálogo:

-Yo, señor alcalde, soy pobre de solemnidad, y vea vueseñoría lo que provee, porque aunque me haga cuartos, no ha de sacarme un cuarto. Perdone, hermano, no hay que dar.

-Pues la carrera de baqueta lo hará bueno.

-Tampoco puede ser, señor alcalde, que aunque soldado, soy hidalgo, y de solar conocido, y mi padre es todo un veinticuatro de Sevilla. Infórmese de mi capitán, don Álvaro Castrillón, y sabrá vueseñoría que gasto un don como el mismo rey, que Dios guarde (ibíd., p. 124).

El diálogo ágil, con argumentos de parte y contraparte hacen del relato un hecho más verosímil. Es decir, el lector aceptará, podrá imaginar, que fue así como sucedieron los hechos entre estos dos personajes.

El alcalde no le aceptó el argumento. Se burló de él y ordenó que le azoten. Y mientras el cronista dice que Aguirre salió herido por el castigo recibido y con la firme convicción que 
debía cobrar venganza matando a Esquivel; en Palma se señala que el soldado se vengaría en sus orejas. Por eso, con algo de sorna, dijo: «Contigo, Antúnez, no va nada [...], pero anuncia al alcalde que desde hoy las orejas que lleva me pertenecen, que se las presto por un año y que me las cuide como a mi mejor prenda» (ibíd.).

Nótese que Palma cambia el planteamiento argumental en lo que se refiere a la forma de tomar venganza. Mientras en la crónica se dice que salió decidido a perseguirlo y buscar el momento de matarlo; en Palma, el soldado que sufrió la afrenta se propone solo cortarle las orejas. El cambio podría parecer extraño, pero no lo es dentro de la lógica de los relatos de Palma porque, a su manera, con ello conseguiría la imagen ridiculizada de un personaje prepotente que termina desorejado.

El personaje de Palma también recurre al asedio. En eso coincide con el cronista. Esquivel será perseguido a todos los lugares que viaje. Con algo de sorna, Cristóbal de Agüero se dejará ver para que sepa que no ha olvidado la afrenta. Y mientras en la crónica el asedio dura tres años y cuatro meses, en el relato de Palma solo dura un año. Transcurrido el tiempo, se le presentó como si fuera un fantasma:

De repente un hombre se descolgó cautelosamente por una ventana del cuarto vecino, dos brazos nervudos sujetaron a Esquivel, una mordaza ahogó sus gritos y fuertes cuerdas ligaron su cuerpo al sillón.

$[\ldots]$

-Señor alcalde mayor -le dijo- hoy se vence el año y vengo por mi honra.

Y con salvaje serenidad rebanó las orejas del infeliz licenciado (ibíd., p.127). 
Luego, como buscando el final feliz, Palma hace aparecer al soldado ante Carlos V quien, al enterarse de la historia, le concede el perdón y le incorpora a un regimiento que iba a México. Final distinto al de la crónica en donde, como vimos, el que sufre la afrenta de honor ve que la única forma de resarcir el deshonor es con la muerte de Esquivel.

\section{3. «Un hombre inmortal»: las argucias para salvar la vida}

Como se sabe, Palma no recurrió como fuente a las crónicas del Inca Garcilaso de la Vega. También consultó los escritos de Diego Fernández, conocido como el Palentino. Ciertamente, en su Historia del Perú, capítulo XII, Fernández da cuenta de un incidente o conspiración para matar a Francisco de Carvajal, el distinguido maestre de campo, cuya vida y aventuras lo convirtieron en leyenda. Dice Fernández:

Vinieron a conjurarse para le matar Luis Perdomo, Alonso Camargo, Pero González de Prado, Diego de Luján, Julián de Humarán, Balboa, Morales de Abad (el Resucitado que llamaron) y era el concierto, que [...] le diesen de puñaladas y matasen también á Alonso de Mendoza y al capitán Castañeda y otros tres o cuatro... (1914, p. 65).

Fernández procede como buen cronista, por eso detalla el nombre de los conspiradores y el acuerdo que tuvieron. Al parecer, estaban decididos. Sabían el riesgo que corrían. Por eso el cronista dice:

Si aquella noche no se efectuaba todo era perdido, y que pues Francisco de Carbajal dormía con tanto recato que no se podía entrar en donde no estaba, que le pusiesen fuego al galpón de su morada y voceando que era muerto alzasen bandera por el rey y apellidasen su nombre [...] luego trajeron allí un crucifijo donde todos juraron de guardar secreto $[\ldots]$ y de ahí a la hora y media, teniendo Carbajal 
aviso de la conjuración, puso gran diligencia para prender los conjurados, poniendo guardas alrededor de la villa para que no huyesen (ibíd., p. 66).

Luego recibió al cura Márquez quien fue a interceder por Alonso Camargo. Iba acompañado de una mujer. Ante ello, Francisco de Carvajal le contó que en un pueblo iban a ejecutar a un personaje honrado y que llevaron una prostituta fea $y$ sucia que decía: «Señores, señores, no matéis al señor Fulano, dádmelo por marido» (ibíd., p. 67). Y es que era la tradición que si una mujer pedía al sentenciado por marido se suspendía la ejecución. Pero, en este caso, el hombrecito: «[...] la vio que debía de ser del arte de esa mujer, y como él era hombre honrado y de tanta presunción, dijo: «Señores, ande el asno, que no quiero tal mujer» (ibíd.).

Como se aprecia, este procedimiento, desde el punto de vista narrativo, se conoce como la técnica de las cajas chinas, es decir, aquella en la que uno abre una caja y luego se encuentra con otra menor. Aquí se trata de una historia breve que se agrega a otra mayor, como sucede con «La historia del curioso impertinente» que Cervantes inserta en El Quijote de la Mancha. En el relato que cuenta Carvajal -su historia dentro de otra historia-, se entiende que el cura ya no insistiría en pedir clemencia por Alonso Camargo.

El cronista agrega la historia de Morales de Abad, otro de los conspiradores que conocían como el Resucitado. Fue sentenciado a la horca como conspirador, pero por una impericia del verdugo no murió. Fue arrojado al río y se salvó. Después le vuelven a apresar. Esta vez, Carvajal está decidido a matarlo si no le dice cuál es el paradero de algunos que faltan: «Señor Morales, pues no me decís dél, yo os prometo que habéis de morir y que no resucitéis agora, porque le harán cuartos y ninguno llevarán al agua» (ibíd., p. 68). 
Palma, en base al relato del cronista, escribe la tradición titulada «Un hombre inmortal» en el que se hace referencia a Morales de Abad. Una vez que develó la conspiración para matarlo, Carvajal ordenaría la ejecución, especialmente de todos los heridos porque, a su entender, cuando estuvieran sanos buscarían cómo vengarse de él. Entonces, para salvar su vida, Morales simuló estar sano:

-Señor don Francisco, conmigo no reza el bando, que yo estoy sano, y apenas si tengo un rasguño que se cura con agua de la fuente.

-Señor Morales -le contestó Carvajal-, juro cierto que vuesa merced está mal herido, y así no puede dejar de morir.

-Protesto, señor don Francisco.

-Pues, hermano de mi alma, la mejor prueba es de que pruebe a andar, que por salvo le doy si de la puerta pasa.

Intentó el sentenciado dar un paso, y cayó exánime de dolor.

-Ahora que estáis convencido, señor Morales -continuó Carbajal-, concluyamos, y que Cantillana haga su oficio (Palma, 1968, p. 103).

Como se verá, una simple referencia de lo acontecido da pie a Palma para recrear la circunstancia a través de diálogos de lo que pudo suceder en esa circunstancia. Palma, como hábil narrador, hará también referencia a las gestiones del Padre Márquez quien quería abogar por Alonso Camargo. Esa historia figura en la crónica de Fernández, y Palma respeta el texto en su estructura, aunque el castellano está más en el nivel de comprensión de los lectores del siglo XIX.

Lo que podemos afirmar, al revisar los casos de reescritura de Palma, es que estamos ante dos paradigmas distintos. A los cronistas le interesa más la referencia de los hechos acontecidos 
y dejan en un segundo plano el arte de la narración y el uso de estrategias que permiten la apreciación en el modo de contar. Para un escritor como Palma, el paradigma es distinto. Para él, lo más importante es ese arte de contar un relato breve. Así pues, su trabajo es más el de un orfebre que debe organizar los hechos acontecidos para mantener el suspenso e intensificar donde sea necesario. Y si recurre a los «parrafillos históricos» es solo con el propósito de reforzar la verosimilitud. Para algunos críticos, ese inserto resulta impertinente porque interrumpe el ritmo narrativo.

\section{Conclusiones}

1. Palma crea con sus tradiciones peruanas un formato que reúne algunas características propias del relato breve, como la recreación ficcional, pero agrega también el denominado «parrafillo histórico» que tendría el propósito de establecer un enlace con los hechos verdaderamente acontecidos. Con ello se vería reforzado el realismo de su relato.

2. Palma sigue la tendencia romántica al recrear hechos del pasado. Palma elige, preferentemente, los acontecimientos o personajes del pasado virreinal y las primeras décadas de la independencia. La particularidad de sus tradiciones es el «puente» que establece entre el pasado y el presente, de manera que el lector encuentre que sus costumbres se remontan al pasado colonial.

3. El tradicionista toma como referencia los relatos de las crónicas y cuenta la misma historia, pero bajo los paradigmas propios de la literatura, en este caso, de la narración breve. Su paradigma es distinto al del paradigma de los cronistas que, se entiende, deben registrar los hechos como historiadores. Estos últimos deben sujetarse a la verdad; mientras el literato se desenvuelve dentro de lo ficcional, lo verosímil. 
4. El estilo de Palma supone una noción de los elementos propios del relato breve: aspectos como la intensidad narrativa, la dosificación de los hechos y el suspenso. Agréguese a ello el estilo depurado del tradicionista al punto que se le puede comparar con la obsesiva perfección de un orfebre.

\section{Referencias bibliográficas}

Acosta, J. (2008). Historia natural y mora de las indias. Madrid: Consejo Superior de Investigaciones científicas.

Compton, M. (2000). La historicidad de las Tradiciones Peruanas de Ricardo Palma. Lima: Fondo editorial Biblioteca Nacional del Perú.

Fernández, D. (1914). Historia del Perú. Madrid: Biblioteca Hispania.

Garcilaso de la Vega, I. (2007). Comentarios reales. Lima: Fondo editorial de la Universidad Inca Garcilaso de la Vega.

Huárag Álvarez, E. (2004). Estructura y estrategias en la narrativa peruana. Lima: Fondo editorial de la PUCP.

Oviedo, José M. (1965). Genio y figura de Ricardo Palma. Buenos Aires: Eudeba Editorial Universitaria.

Palma, R. (1968). Tradiciones peruanas completas. Madrid: Ediciones Aguilar.

Zavaleta, C. E. (1998). «Naturaleza y estructura de la tradición de Palma». En Aula Palma No 1. Discurso de incorporación, pp. 219-237. Lima: Universidad Ricardo Palma, 1998. 
